\title{
Mastalgia: A narrative literature review of current understanding and management
}

\author{
Sajad A. Salati', Ahmed A. Alhumaid ${ }^{2}$ \\ 1. Unaizah College of Medicine, Qassim University, Unayzah, Saudi Arabia \\ 2. Qassim College of Medicine, Qassim University, Buraydah, Saudi Arabia \\ Correspondence: Dr Sajad A. Salati (docsajad@gmail.com)
}

\begin{abstract}
C 2018 S.A. Salati \& A.A. Alhumaid. This open access article is licensed under a (reative Commons Attribution 4.0 International License (http://creativecommons.org/licenses/by/4.0/), which permits unrestricted use, distribution, and reproduction in any medium, provided you give appropriate credit to the original author(s) and the source, provide a link to the Creative Commons license, and indicate if changes were made.
\end{abstract}

East Cent Afr J Surg. 2018 Apr;23(1):42-51 https://dx.doi.org/10.4314/ecajs.v23i1.9

\begin{abstract}
Mastalgia, or breast pain, is one of the most common breast symptoms experienced by women of reproductive age. The cyclical variant of mastalgia is predominant, and patients need proper assessment and management to allay their 2 chief concerns: (1) the severity of pain negatively impacting daily life and (2) the fear of harbouring malignancy. This article presents a brief review of various modalities of management for cyclical mastalgia and emphasizes data collected from peer-reviewed literature published in the last decade.
\end{abstract}

Keywords: mastalgia, breast pain, mastodynia, mammalgia, cyclic mastalgia, noncyclic mastalgia, danazol, tamoxifen, reassurance, visual analogue scale

\section{Introduction}

Mastalgia, or breast pain (or mastodynia), is globally a common symptom experienced by women of reproductive age; the reported prevalence ranges from $41 \%$ to $79 \% .{ }^{1-3}$ Data reported in this narrative review were obtained from randomized controlled trials, observational studies, and review articles through PubMed, PubMed Central, HINARI, Google Scholar, and Medline Internet searches, with an emphasis on studies published in the last 2 decades. The terms searched included "mastalgia", "mastodynia", "breast pain", "cyclic mastalgia" and "noncyclic mastalgia".

Mastalgia is typically approached according to its classification, of which there are three types:

1. Cyclic mastalgia - Cyclic breast pain occurs 1 to 2 weeks before, and is relieved by, the onset of menstruation. The pain is generally diffuse and bilateral though it may be more severe on 1 side than the other and radiate to the upper arm and axilla. The pain is often described as sharp, shooting, stabbing, heavy, aching, deep tenderness, or throbbing. Patients are usually in their fourth or fifth decade of life. Cyclic mastalgia may resolve spontaneously in up to $22 \%$ of cases, or resolution may occur with a hormonal event, such as pregnancy or menopause. The condition may persist in up to $65 \%$ of cases after treatment, and the suffering may continue until the onset of menopause.
It has been stressed that cyclical mastalgia, although associated with the menstrual cycle, is not merely premenstrual syndrome (PMS) but is a separate entity with a different presentation, aetiology, and effective treatment and although mastalgia is a well-documented symptom of PMS, it is possible for cyclic mastalgia to occur outside of the context of PMS. ${ }^{4}$

2. Noncyclic mastalgia - The breast pain bears no relation to menses. It is usually unilateral, localized to a particular quadrant of the breast, and may be constant or intermittent. Patients are usually older and are often perimenopausal. Pain tends to be well localized and often subareolar or medial; it may also be bilateral and is often described as heavy, aching, tender, burning, pulling, stabbing, or pinching.

Various lesions can cause noncyclical mastalgia, a classification that includes cysts, periductal mastitis, stretching of Cooper's ligaments, traumatic fat necrosis, Mondor's disease, diabetic mastopathy, and even neoplasia. ${ }^{4}$ Some women have a localized tender area-the trigger spot-in the affected breast. Noncyclic mastalgia can resolve without treatment in up to $50 \%$ of cases, but can it also be more challenging to treat and needs 
sufficient evaluation to define the causative factor and to rule out neoplasia. ${ }^{5,6}$

3. Extramammary (nonbreast) pain - Extramammary pain arises from structures other than the breast but mimics breast pain. Patients can belong to any age group. The origin of pain includes the chest wall or outside the chest wall. Common chest wall conditions include costochondritis (chondropathia tuberosa, Tietze syndrome), referred nerve root pain from spinal compression or spondylosis, surgical trauma, and herpes zoster. Other conditions causing extramammary breast pain include diverse causes, such as ischemic heart disease, biliary pain, oesophagitis, and peptic ulcer disease. The pain is almost always unilateral.

Ader and Shriver, in $1997,{ }^{7}$ reported the results of a descriptive study of 231 women under 55 years of age who visited a single breast clinic. They found that $30 \%$ of premenstrual women suffered from cyclic mastalgia lasting for 5 days or more in a month, and the "clinical" level of mastalgia interfered with usual sexual activity for 33\%, with physical activity for $29 \%$, with social activity for $15 \%$, and with work for $15 \%$ of the women. The study further found that young women ( $\leq 35$ years old) were more than three times as likely to have had a mammogram $(75 \%)$ if they regularly experienced cyclic mastalgia than if they did not $(24 \% ; P<0.05)$ thereby putting pressure on the healthcare system. Hence, the authors suggested that mastalgia should not be ignored but subjected to further biopsychosocial investigation.

Scurr et al., in 2014, ${ }^{8}$ presented the results of a global study that examined the prevalence, severity, and impact of breast pain among 1659 females (mean age $34.1 \pm 13.2$ years). The study found that over half of the sample (51.5\%) experienced breast pain with a severity similar to that reported in clinical populations. Of the symptomatic participants, $41 \%$ and $35 \%$ reported breast pain affecting the quality of life measures of sex and sleep, respectively. Moreover, $10 \%$ of symptomatic participants had suffered breast pain for over half their lives. The results of this study proved that mastalgia is a significant health-related issue within the general population. The same study showed that there was a higher prevalence of breast pain in older participants, larger-breasted participants, and those who were less fit and active. The reported relationship between breast pain and fitness and activity levels may offer an alternative treatment in the form of exercise intervention strategies to reduce breast pain.

Brown et al. ${ }^{9}$ conducted a study to evaluate breast pain among female runners who participated in the 2012 London Marathon. They found that mastalgia was present in onethird of the 1285 participants and about $56 \%$ of the sufferers required medication.

\section{Aetiology of mastalgia}

The aetiology of mastalgia is not clearly understood. Hormonal assays of oestrogen, progesterone, and prolactin have shown inconsistent abnormalities despite the relationship of the cyclic variant to the menstrual cycle. The major aetiological factors mentioned in the literature include:

\section{Endocrine abnormalities}

Two main theories have emerged regarding the aetiology of mastalgia:

1. Oestrogen - Increased oestrogen secretion and deficient progesterone production during the luteal phase of the menstrual cycle leading to hormonal imbalance.

The studies of serum hormones levels do not support the hormone imbalance theory, as hormonal levels were found to be similar in patients and controls in earlier studies conducted by Malarkey et al., ${ }^{10}$ though Sitruk et al. ${ }^{11}$ showed a significantly depressed level of luteal progesterone, thus supporting the hormone imbalance theory.

2. Hyperprolactinaemia - Peters et al. found that patients with mastalgia had significantly higher levels of prolactin compared with controls. ${ }^{12}$ Kumar et al. tested pituitary function in benign breast disorders and found a significant abnormality in patients with severe cyclic mastalgia $(P<0.05)$, but not in those with noncyclic mastalgia. ${ }^{13}$ No abnormalities of thyroid function were found. Another study by Kumar et al. indicated that dynamic tests of prolactin released in cyclic mastalgia may be useful in predicting a subsequent satisfactory response to endocrine therapy. ${ }^{14}$

\section{Water retention}

A traditional view has been that there is a premenstrual increase in total body water and that this causes mastalgia. However, an impressive study was undertaken by Preece et al., at the Cardiff Mastalgia Clinic, ${ }^{15}$ in which total body water (TBW) was measured early and late in the menstrual cycles of 56 women, 39 of whom had breast pain. It was found that in some cases TBW actually decreased, while in others there was no change from the early cycle measurement. No TBW pattern correlated with any syndrome of breast pain or with any psychoneurotic profile.

\section{Psychoneurosis}

Multiple studies have demonstrated an association between mastalgia, particularly the treatment-resistant variant, and various psychological symptoms, such as depression, anxiety, history of emotional abuse, and somatization. ${ }^{16-17}$

Johnson et al., after studying the pattern of mastalgia in female veterans, hypothesized that, like somatization, frequent mastalgia may also be associated with psychiatric conditions and may cluster with unexplained pain syndromes. ${ }^{18}$

\section{Miscellaneous factors}

\section{Caffeine and methylxanthines}

Caffeine is frequently listed as a causal factor for mastalgia, and Ader et al. ${ }^{1}$ and Eren et al. ${ }^{19}$ both found a significant 
association $(P<0.05)$ between caffeine consumption and breast pain in their studies. Minton and Abou-Issa, in 1989, published the summarized results of 15 years of clinical and laboratory studies that had been undertaken to search for a biochemical basis for the development and resolution of symptomatic benign fibrocystic disease. They found that caffeine restriction produced significant improvement in the symptoms of many women. ${ }^{20}$ It has been suggested that overstimulation of breast cells may occur due to interference with adenosine triphosphate degradation by methylxanthines present in tea, coffee, cola, and chocolate; however, Millet and Dirbas did not find any significant benefit following the exclusion of such items from the diet of mastalgia patients. ${ }^{21}$

\section{Smoking}

Smoking has been attributed to increased breast pain by increasing epinephrine levels in the breast. Eren et al. found a statistically significant association $(P<0.05)$ between cigarette smoking and mastalgia. ${ }^{19}$ Ader et al. found that smoking was associated with mastalgia (odds ratio $=1.52){ }^{7}$

\section{Aberration in lipid metabolism}

Multiple therapeutic and investigative studies have been published that suggest the possibility of the role of lipid profile aberrations in the pathophysiology of mastalgia in general and cyclic mastalgia in particular. Sharma et al. conducted a prospective study with the aim of looking for such aberrations. ${ }^{22}$ They enrolled 57 patients who had been symptomatic for at least 6 months before presentation, and a detailed serum lipid profile workup was performed on days 1,15 , and 25 of their menstrual cycles. The patients with symptoms of maximal severity during (or limited to) the luteal phase of the menstrual cycle were included in group I $(n=32)$, whereas those who had mastalgia but no cyclical variation were included in group II $(n=25)$. The subjects in group II were treated as controls. At day 25, there was an elevation in mean values of high-density lipoproteins cholesterol (HDL-C) $(P=0.03)$ and the HDL-C/low-density lipoproteins cholesterol (LDL-C) ratio $(P=0.01)$. There was also a reduction in the total cholesterol $(\mathrm{TC}) / \mathrm{HDL}-\mathrm{C}$ ratio $(P<0.03)$ in group I and no such changes were observed in group II patients. Furthermore, when the mastalgia patients were treated with a low-fat dietary regimen, there was a significant difference in the responses of these 2 groups $(P<0.0001)$. The authors concluded that cyclic mastalgia is an entity that is distinctly different from noncyclic mastalgia and has links to lipid metabolism aberrations.

The breast tissue of women with mastalgia is believed by some to be high in saturated fatty acids and deficient in gamma-linolenic acid (GLA), which renders it abnormally sensitive to normal hormone levels, thus resulting in pain. ${ }^{23}$ With prolonged high-dose treatment $(320 \mathrm{mg} /$ day for 3 to 6 months), the GLA content of evening primrose oil (EPO) restores the balance of fatty acids in the breast tissue, with high efficacy and few side effects. ${ }^{23}$

\section{Mastalgia and breast cancer}

There may be an association between mastalgia and the subsequent development of breast cancer, but the nature of the relationship is not clear based on current evidence. Some researchers have questioned whether breast pain is truly related to cancer or whether this pain prompts an evaluation in which an otherwise asymptomatic cancer is identified. ${ }^{24}$ It is very rare to have mastalgia as the only symptom of breast cancer, though breast pain has been reported along with other symptoms of breast cancer in the range of $5 \%$ to $18 \%$ of cases of breast cancers. Cochrane et al. conducted a retrospective study of 2332 new patients attending a breast clinic in South Wales and found that only 1 cancer presented with mastalgia alone. ${ }^{25} \mathrm{Plu}$-Bureau et al. conducted a casecontrol study of 420 premenopausal women matched for age and age at first full-term pregnancy and found that a history of cyclic mastalgia was associated with an increased risk of breast cancer. ${ }^{26}$ Another study conducted by Goodwin et al. included 192 premenopausal women recently diagnosed with node-negative breast cancer who were age-matched with 192 controls, and the results pointed towards an association between cyclic breast tenderness with breast cancer risk in premenopausal women. ${ }^{27}$ Khan and Apkarian studied the association between mastalgia and breast cancer by analysing data for 5463 women who attended the Breast Care Center of University Hospital, Syracuse, New York, and after making adjustments for various risk factors (early menarche, late first birth, late menopause, exogenous hormone use, and positive family history), it was found that women who experienced pain were less likely to be diagnosed with breast cancer. ${ }^{28}$ Conversely, a study by Preece et al. found that 36 of 240 women with newly diagnosed breast cancer had localized breast pain as a presenting symptom. Of these, 10 women (28\%) had normal mammographic findings and were later diagnosed as having subclinical breast cancer at the site of pain after further evaluation. ${ }^{29}$ Therefore, cancer must be seriously considered as a differential diagnosis in patients presenting with well-localized breast pain. These patients should be followed up on for at least 1 year after the onset of the pain before cancer is confidently excluded. ${ }^{29,30}$

\section{Histologic associations}

Studies undertaken for identification of underlying histopathological diagnoses in mastalgia patients have shown an inconsistent association of breast pain with fibrocystic histology. In a study conducted by Watt-Boolsen et al., the fibrocystic histologic findings of intraductal proliferation, adenosis, sclerosing adenosis, duct ectasia, intraductal debris, papillomatosis, apocrine metaplasia, microcysts, and proliferative periductal connective tissue were common but without any statistically significant difference among groups with cyclic breast pain, noncyclic pain, and no symptoms. ${ }^{31}$ In a study involving 39 women with cyclic breast pain who underwent breast biopsy, Jorgensen and Watt-Boolsen ${ }^{32}$ found that all had fibrocystic histologic changes. However, a similar set of changes were also present in 61 of 68 women without breast pain who underwent biopsy for other reasons. Additionally, it has been established by various other studies ${ }^{33-35}$ 
that, except for proliferative changes or cellular atypia, histologic changes do not confer an increased risk of breast cancer and that these histologic findings are to be considered part of the spectrum of normal involution in the breast. Ramakrishnan et al. studied the potential role of inflammation and inflammatory cytokines in mastalgia and found that there was no difference between 29 premenopausal women with breast pain and 29 matched asymptomatic women regarding the degree of inflammatory cell infiltration and cytokine (interleukin 6 and tumour necrosis factor-alpha) expression in breast tissue specimens. ${ }^{36}$

\section{Clinical assessment and investigations}

Clinical assessment of mastalgia cases includes a detailed history to determine the nature, severity, timing, and duration of the pain. The relationship of pain to the menstrual cycle and its impact on work and routine activities are important. History must include relevant questions to stratify the patient's risk of breast cancer, such as the family history and oestrogen window. After history building, there should be a careful examination of the breasts and axillae. Particular attention should be paid to extramammary causes of breast pain and specifically the possibility of costochondral pain, in the case of noncyclic mastalgia.

Investigations in cases presenting with mastalgia are undertaken with the aim of screening for breast cancer. Though mastalgia is not a common presenting symptom of breast cancer, it does present an opportunity for screening for an otherwise common cancer, particularly in regions where there is generally poor access to dedicated breast care centres.

Radiologic investigation is, however, not indicated in young women with no risk factors and normal breast examination findings. Mammography is recommended for women over 35, those with a positive family history, and patients with noncyclic mastalgia. Ultrasound examination is helpful if there is a clinically palpable lesion or if the patient presents with localized noncyclic pain. The negative predictive value of a proper clinical examination, combined with mammography or ultrasound, approaches $100 \% .{ }^{37}$ If the physical examination or radiology identifies an abnormality, such as a breast lump, this must be thoroughly investigated to complete the standard "triple assessment". ${ }^{6}$

\section{Breast pain assessment}

Assessment and quantification of breast pain may be difficult due to the wide variability. ${ }^{24}$ Pain may wax and wane without any provocation, with specific activities, or with the menstrual cycle. Assessment with the use of common pain-rating instruments, such as a visual analogue scale (VAS) or numerical rating scale (NRS), may be helpful in evaluating breast pain, for making decisions regarding treatment, and for monitoring responses to therapy. Daily breast pain diaries have been found to be useful in management after prospective documentation of the occurrence and severity of pain, aggravating and alleviating factors, use of medications, and interference with lifestyle. ${ }^{4,6}$ These diaries are more accurate and complete than mere recall of symptoms by patients. ${ }^{6}$ In a study by Khan and Apkarian, a modified version of the McGill Pain Questionnaire (SF-MPQ) was administered to 271 women with cyclic or noncyclic breast pain, and the mean pain rating index was found to be 12.0 out of 45 ; similar to pain ratings in cases of rheumatoid arthritis and cancer. ${ }^{38}$

\section{Management of mastalgia}

The management of mastalgia can be broadly divided into nonpharmacological interventions and pharmacologic interventions.

\section{Nonpharmacologic and alternative interventions}

Nonpharmacologic interventions have frequently been found to improve mastalgia in clinical practice ${ }^{39}$ and are of low risk and expense to the patient, although there have been fewer scientific studies into the effectiveness of these interventions.

\section{Reassurance}

Reassurance, re-evaluation, and proper explanation of the condition have vital roles in the treatment of women with mastalgia. ${ }^{40}$ Barros et al. conducted a study on 121 women suffering from mastalgia to evaluate the results of the application of a nonpharmacologic treatment based on explanation and reassurance. ${ }^{41}$ The subjects received reassurance and information and were followed up with a questionnaire 2-3 months later, and comparison of pain parameters of the patients before and after reassurance was made. The authors reported a success rate of $70.2 \%(n=85)$ with reassurance. Upon evaluation of subjective pain intensity reporting, reassurance was effective in $85.7 \%$ of the patients with a mild form of mastalgia, in $70.8 \%$ with a moderate form, and in $52.3 \%$ with a severe form. The study concluded that reassurance should be the first-line treatment for women with mastalgia and pharmacological management should be reserved only in the cases refractory to this form of management.

Vaidyanathan et al. stressed the need for education and regulation of continuous professional development for physicians so that they can distinguish benign breast conditions from malignant ones and know when to reassure or refer patients to specialists for evaluation. ${ }^{42}$

\section{Physical measures}

Improved external mechanical support has been found to relieve breast pain, and many studies have been conducted on the therapeutic value of a supporting brassiere in mastalgia. Be-Lieu found that about $70 \%$ of women wear an improperly fitted brassiere. ${ }^{43}$ Symptomatic women may benefit from advice regarding proper selection and fitting of a brassiere, with recommendations for wearing a soft, supportive brassiere during sleep and use of a sports bra during exercise. ${ }^{44}$ Wilson and Sellwood conducted an interventional study that enrolled 114 women whose mastalgia lasted more than 7 days in each menstrual cycle, interfering with daily life or sleep, and severe enough to require treatment. ${ }^{45}$ Subjects 
were provided with 2 properly fitting brassieres and counselled about the correct technique for wearing a brassiere by a trained nurse and monitored at 3-month intervals for up to 18 months. One hundred of the subjects completed follow-up, and 26 of them experienced complete relief, 49 experienced an improvement in pain, 21 had neither improved nor worsened pain, and 4 experienced worsened pain. Furthermore, 11 of 15 patients who had required medication for breast pain experienced improvement or relief with this intervention.

\section{Exercise}

Exercise has been found to have a positive impact in the alleviation of symptoms in many severe cases of chronic pain, fibromyalgia, and chronic fatigue syndrome. Genc et al. undertook a randomized controlled trial to study the impact of exercise on mastalgia. Mastalgia patients were randomly assigned to a control group and an exercise group. The use of a sports brassiere, abstention from food containing caffeine and methylxanthines, and simple analgesics were recommended for both groups, and an exercise programme intervention was added for the exercise group. The exercises were conducted 3 times per week for 6 weeks. Participants were evaluated for breast pain before and 6 weeks after the study. Serum cytokine levels were also collected and analysed. The study concluded that the exercise treatment is beneficial for patients with mastalgia and that it can be suggested by clinicians. ${ }^{46}$

\section{Diet and nutritional intervention}

A low-fat, high-carbohydrate diet and weight reduction have been proven to result in a reduction in hormones, such as prolactin, and relieve the intensity of breast pain. ${ }^{22,47}$

In a single-blind, randomized, controlled study, Boyd et al. assessed the effect of a low-fat diet (15\% energy from fat) on severe cyclic mastalgia and found that reduced swelling, tenderness, and nodularity were reported in $60 \%$ of patients in the intervention group. ${ }^{48}$

The role of dietary modification in the form of caffeine restriction is still controversial as mentioned above in the section on aetiology. While Minton and Abou-Issa examined cases of fibrocystic disease and found that caffeine restriction produced significant symptomatic improvement in many women, Millet and Dirbas ${ }^{21}$ and Anjum et al. ${ }^{49}$ found no significant relationship between breast pain with caffeine intake.

\section{Relaxation therapy}

Given the involvement of psychological elements in the aetiology of mastalgia, relaxation therapy (RT) has been proposed as a treatment for breast pain. Fox et al. recruited 45 women with mastalgia severe enough to warrant evaluation and treatment to a randomized clinical trial of daily pain diary keeping and RT versus diary keeping on its own (control). The study lasted for 12 weeks; women assigned to RT practised daily with an audio cassette recording during weeks 5-8. Women who received RT showed significant improvement, compared to the control group, as assessed by the Car- diff Breast Scale $(P=0.05)$. The study suggested that RT may be more effective for cyclic than noncyclic mastalgia. ${ }^{50}$

\section{Evening primrose oil}

The role of EPO in the management of mastalgia is controversial. As mentioned above in the aetiology, breast tissue is abnormally sensitive to normal oestrogen levels due to the relative deficiency of GLA. With prolonged high-dose treatment ( $320 \mathrm{mg}$ /day for 3 to 6 months), the GLA content of EPO has been found to restore the balance of fatty acids in the breast tissue, with high efficacy and minimal side effects. ${ }^{23,51}$

However, many other studies including certain randomized, placebo-controlled, double-blind clinical trials have found EPO to have no efficacy in the treatment of cyclic mastalgia. ${ }^{52-54}$

Trials have been conducted in which EPO was administered along with some other elements with equivocal results. Pruthi et al. conducted a double-blind, randomized, placebo-controlled trial at 2 academic medical centres in the United States to evaluate the effectiveness of vitamin E, EPO, and a combination of vitamin E and EPO for pain control in women with cyclic mastalgia. They concluded that daily doses of 1200 IU vitamin E, or $3000 \mathrm{mg}$ EPO, or a combination of these same doses of vitamin E and EPO, taken for 6 months, may decrease the severity of cyclic mastalgia. ${ }^{55}$

Blommers et al. conducted a randomized, double-blind, factorial clinical trial to evaluate the effect of EPO and fish oil on breast pain in premenopausal women with severe chronic mastalgia. ${ }^{56}$ They placed 120 women randomly into 4 groups and orally administered (a) fish oil and control oil, (b) evening primrose oil and control oil, (c) fish oil and evening primrose oil, or (d) both control oils. Corn oil and corn oil with wheat germ oil were used as control oils. The change in the percentage of days with breast pain after 6 months of treatment was analysed on an intention-to-treat basis, and it was concluded that all the groups showed a decrease in pain and neither EPO nor fish oil offered a clear benefit over control oils in the treatment of mastalgia.

\section{Phytoestrogens}

Phytoestrogens or dietary oestrogens are plant-derived xenoestrogens not generated within the endocrine system but consumed by eating phytoestrogenic plants. They are a diverse group of naturally occurring nonsteroidal plant compounds that, because of their structural similarity with oestradiol (17 $\beta$-oestradiol), can cause oestrogenic or anti-oestrogenic effects. In this category, studies have been conducted on 2 sources, as described below:

\section{Isoflavones}

Ingram et al. conducted a small, double-blind, randomized, controlled trial to study the roles of isoflavones in the treatment of cyclical breast pain..$^{57} \mathrm{~A}$ total of 18 women were randomized to receive a placebo or $40 \mathrm{mg}$ isoflavones or $80 \mathrm{mg}$ isoflavones. It demonstrated that isoflavones led to a significant reduction in cyclic mastalgia ( $13 \%$ for placebo, $44 \%$ for $40 \mathrm{mg}$ of isoflavones per day, and $31 \%$ for $80 \mathrm{mg}$ per day). 


\section{Flaxseed}

Goss et al. examined the effects of dietary flaxseed in women with severe cyclic mastalgia. ${ }^{58}$ A total of 116 women were enrolled in the double-blind, placebo-controlled trial with the treatment group receiving $25 \mathrm{~g}$ of flaxseed daily, in a muffin, and monitored for up to 4 menstrual cycles. Breast pain was alleviated in both treatment groups but was reduced to a significantly higher degree in the flaxseed group.

\section{Topical Nigella sativa seed oil}

Huseini et al. conducted a randomized, triple-blind, active, and placebo-controlled clinical trial to study the effectiveness of topical Nigella sativa seed oil in the treatment of mastalgia. ${ }^{59}$ Standardized N. sativa seed oil (600 mg) was applied to the site of pain twice daily for 2 months in 52 women, and the impact on pain was compared-using a visual analogue scale- to that of topical diclofenac (20 mg twice daily in 51 women) and placebo $(n=53)$. The study found that the pain scores of the active treatment groups at 1 and 2 months were significantly lower than those of the placebo group (both $P<0.001)$ and the pain scores of the placebo group at 1 and 2 months were not significantly different from the baseline $(\mathrm{P}>0.05)$. No adverse effects were observed. It was concluded that the topical $N$. sativa seed oil is safe, more effective than placebo, and has a clinical effectiveness comparable to topical diclofenac in the treatment of cyclic mastalgia.

\section{Vitex agnus-castus (Chaste tree) berry extract}

Vitex agnus-castus L., commonly known as Agnus Castus or the Chaste tree, is a deciduous shrub native to Mediterranean Europe and Central Asia. It is postulated that V. agnus-castus fruit extract suppresses stress-induced latent hyperprolactinaemia by blocking the dopamine- 2 receptor type on the pituitary gland, thereby relieving cyclic mastalgia. The adverse events following V. agnus-castus treatment have been found to be mild and reversible. Carmichael studied the data from randomized and nonrandomized studies regarding the efficacy and safety of $V$. agnus-castus in a systematic fashion and concluded that $V$. agnus-castus can be considered an effective alternative phytotherapeutic agent in the treatment of mastalgia. ${ }^{60}$

Halaska et al. conducted a placebo-controlled, randomized, double-blind study and investigated the efficacy of a $V$. agnus castus extract-containing solution (VACS) in patients suffering from cyclic mastalgia, and found VACS to be effective and well tolerated. ${ }^{61}$

\section{Low-intensity laser therapy}

Low-intensity laser therapy (LILT) has been recently proposed as a tool for the management of mastalgia. Saied et al. conducted a double-blind study on 80 patients with cyclic mastalgia after randomly dividing them into 2 groups (A and $B)$. In group A, patients were treated with bromocriptine and EPO; in group B, LILT was applied with specified dosimetry, using a device that delivers He-Ne laser combined with 4 infrared diode lasers. Evaluation of treatment was both subjective (using a visual analogue scale) and objective (studying the degree of drop in plasma cortisol levels). A good response was observed in the laser group (82.5\%) compared to $63.9 \%$ in the bromocriptine/EPO group. There was a significant improvement in pain in both the groups $(P<0.05)$, but pain was alleviated in a broader range of patients in the LILT group. ${ }^{62}$

\section{Pharmacologic interventions}

\section{Progesterone}

McFadyen et al. found that progesterone cream applied locally was no better than placebo cream in relieving mastalgia. ${ }^{63}$ Along similar lines, a small, randomized, double-blind crossover study $(\mathrm{N}=26)$ by Maddox et al. concluded that the therapeutic response of $20 \mathrm{mg}$ /day of oral medroxyprogesterone acetate during the luteal phase was no better than a placebo in the management of cyclic mastalgia. ${ }^{64}$ However, in a randomized, double-blind, placebo-controlled study conducted in Italy by Nappi et al., a vaginal cream of micronized progesterone was found to be effective in reducing pain in $64.9 \%$ of cases, compared with $22.2 \%$ of controls. ${ }^{65}$

\section{Ormeloxifene (centchroman)}

Ormeloxifene, also known as centchroman, is a selective oestrogen receptor modulator (SERM). It is best known as a nonhormonal, nonsteroidal oral contraceptive that is taken once per week. Rathi et al. conducted a prospective, open-label, single-arm study using the pretest-posttest design. ${ }^{66} \mathrm{~A}$ total of 100 women suffering from moderate to severe mastalgia were enrolled and received $30 \mathrm{mg} /$ day of centchroman for 12 weeks followed by observation for 12 weeks. Complete response was observed in $66 \%$ of cyclic mastalgia and $40 \%$ of noncyclic mastalgia patients after 1 week of therapy, and the improvements continued over time in both groups and at completion of treatment (12 weeks) $92 \%$ of patients in the cyclic group and $80 \%$ of patients in the noncyclic group were pain free. The positive impact of the drug persisted at 24 weeks $(P=0.001)$. The study found centchroman to be effective in treating mastalgia, and the authors recommend its use as a first-line drug.

Dhar and Srivastava conducted a similar study on 60 mastalgia patients and recorded a decrease in visual analogue scale scoring from 10 to 3 in $90 \%$ of the patients at the end of the first week, and almost all of the patients were painless at the end of 1 month. ${ }^{67}$ Tejwani et al. conducted a randomized, controlled trial of centchroman versus danazol, in the management of mastalgia, involving 81 patients. ${ }^{68}$ Of these 81 patients, 39 were randomized to the danazol arm and 42 to the centchroman arm. Treatment was given for 12 weeks, followed by an observation period of 12 weeks. A reduction in pain score to $\leq 3$ was achieved by $89.7 \%$ of women in the centchroman group $(P=0.001)$ at 12 weeks and $69.44 \%$ of women in the danazol group $(P=0.001)$. Three months after stopping therapy, centchroman was more effective than danazol in terms of pain reduction at 24 weeks $(P=0.019)$. The study concluded that centchroman is an effective, safe and inexpensive treatment for mastalgia. 


\section{Toremifene}

Toremifene citrate is an oral SERM that predominantly has anti-oestrogenic properties with minimal oestrogenic activity. Hamed et al. investigated this drug in the treatment of mastalgia and evaluated its tolerability and efficacy by enrolling 17 premenopausal women, with a mean age of 37.7 years, complaining of moderate to severe mastalgia (70\% of patients with cyclic and $30 \%$ with noncyclic mastalgia). ${ }^{69} \mathrm{~A}$ dose of $60 \mathrm{mg}$ toremifene was administered daily. The proposed treatment period was to be 12 weeks, but 4 patients (23.5\%) withdrew from the study after 4 weeks because of side effects. All women with cyclic mastalgia responded to toremifene, compared with only $75 \%$ of those with noncyclic mastalgia. This study concluded that toremifene is an effective agent in the treatment of mastalgia, but a high incidence of side effects makes it ineligible as an agent of choice.

On the other hand, Gong et al., after a double-blind, randomized controlled trial, concluded that toremifene is a feasible therapy for moderate and severe mastalgia, especially cyclic mastalgia with tolerable adverse effects. ${ }^{70}$

\section{Topical nonsteroidal anti-inflammatory drugs}

Many studies have found that topical nonsteroidal anti-inflammatory drugs (NSAIDs) are effective in relieving breast pain, and these may be considered as a first-line treatment, as the benefits are thought to outweigh the risk of adverse effects. Irving and Morrison, in their prospective pilot study, demonstrated the potential for effective treatment of cyclic and noncyclic mastalgia using stronger types of topical NSAIDs-diclofenac and piroxicam. ${ }^{71}$ Colak et al. conducted a prospective, randomized, blinded, placebo-controlled study $(\mathrm{N}=108)$ and demonstrated a significant improvement with topical diclofenac diethylammonium (Emulgel) in the treatment group, for both cyclic and noncyclic mastalgia, with minimal side effects after application for 6 months. ${ }^{72}$ The authors proposed the topical gel as a reasonable alternative to a systemic analgesic.

\section{Danazol}

Danazol is a synthetic testosterone that binds to progesterone and androgen receptors, although the precise mechanism of action in the treatment of mastalgia is unknown. Multiple studies conducted over the last 4 decades have proven the benefits of $200 \mathrm{mg}$ of danazol per day. Mansel et al. compared danazol $200 \mathrm{mg} /$ day with a placebo in 28 women with cyclic mastalgia, with crossover at 3 months, and mean pain scores showed a significant response to danazol. ${ }^{73}$ Ortiz-Mendoza and Olvera-Mancilla achieved control of moderate to severe, cyclic and noncyclic mastalgia in about $80 \%$ of patients, though adverse effects were documented in $20.6 \%$ of cases. ${ }^{74}$

The drawback with the use of danazol is the appearance of adverse effects in more than $50 \%$ of patients; these include weight gain, hirsutism, menstrual irregularity (amenorrhoea or menorrhagia), deepening of the voice, and hot flushes. Studies have been conducted on lower doses of danazol to investigate options that minimize adverse effects. Furthermore, there is a possibility of recurrence in up to $50 \%$ of patients on discontinuation of treatment. O'Brien and Abu Khalil evaluated the efficacy and side effects of danazol $200 \mathrm{mg} /$ day, with administration limited to only during the luteal phase of the menstrual cycle, and demonstrated effective relief of cyclic mastalgia and minimal side effects. ${ }^{75}$

Maddox et al. $^{76}$ and Harrison et al. ${ }^{77}$ also conducted studies on the impact of low doses of danazol administered during the luteal phase and concluded that a low-dose regimen may be suitable for women with chronic, relapsing cyclic mastalgia or those who develop side effects on standard doses.

\section{Tamoxifen}

Tamoxifen is an effective treatment to control moderate to severe mastalgia and, like danazol, can be prescribed when first-line treatments are ineffective. Multiple studies have proven its effectiveness. In a study conducted by Ortiz-Mendoza et al., involving 141 cases, tamoxifen achieved pain control in $67 \%$ of patients, and 64 patients (45\%) showed side effects $(9.7 \%$ with $10 \mathrm{mg}$ and $41.6 \%$ with $20 \mathrm{mg} ; P<0.001)$, with dizziness and headache being the most frequent and significant side effects. ${ }^{78}$ Only 8 patients (5.6\%) stopped treatment. In a double-blind, randomized, controlled trial, Fentiman et al. observed significant pain relief in $75 \%$ of patients treated with tamoxifen $20 \mathrm{mg}$ /day over 3 months. ${ }^{79}$ The most frequent side effects were hot flushes (27\%) and vaginal discharge (17\%).

Kontostolis et al. compared the benefits and side effects of tamoxifen versus danazol in women with severe cyclic mastalgia and found tamoxifen to be highly efficacious and more cost-effective. ${ }^{80}$ Jain et al. compared the outcomes of tamoxifen therapy with centchroman (ormeloxifene) and found the 2 to be of similar effectiveness in providing pain relief for mastalgia. ${ }^{81}$

\section{Bromocriptine}

Bromocriptine is a dopamine agonist that stimulates the dopaminergic receptors in the anterior pituitary, thereby blocking the release of prolactin. It is administered at an oral dose of $2.5 \mathrm{mg}$ twice daily. In a meta-analysis conducted by Srivastava et al., bromocriptine was found to offer a reduction in the weighted mean pain score equal to -16.31 (95\% confidence interval $[\mathrm{CI}]=-26.35$ to -6.27$){ }^{82}$

In a randomized, controlled, multicentre trial of 3 and 6 months of treatment, Mansel and Dogliotti found bromocriptine to be effective; however, adverse effects, including headaches and dizziness, resulted in a high dropout rate in this study. ${ }^{83}$ Similarly, in a study by Nazli et al., bromocriptine was found to produce complete relief of symptoms in $65 \%$ of cases, but side effects were experienced by $40 \%$ of subjects. ${ }^{84}$ Due to the high incidence of adverse effects, bromocriptine is reserved for exceptional cases where other measures do not work or are contraindicated.

\section{Surgical intervention}

Surgical interventions have a limited role in the management of mastalgia and data about this option are sparse in 
the literature. Davies et al., after a retrospective study conducted at the University Hospital of Wales, Cardiff, concluded that surgery for mastalgia should be considered only for a minority of women who are resistant to all other forms of treatment. The authors stressed that, before any surgical procedure, patients must be informed of possible complications inherent in reconstructive surgery and warned that in 50\% of cases their pain will not improve. ${ }^{85}$ Steinbrunn et al. proposed that surgery can be useful for selected patients with a discrete, small trigger spot when the symptoms may be relieved by excision of that spot. ${ }^{86}$

\section{Long-term course of mastalgia}

The course of mastalgia is generally long. Davies et al. found that the median age of onset of breast pain was 36 years (range $12-63$ years).$^{87}$ The median duration of pain was found to be 12 years. Pain persisted in 68 cyclic mastalgia patients (57\%) and 35 noncyclic mastalgia patients (64\%). In cyclic mastalgia, pain resolution was commonly associated with a "hormonal event", notably menopause; in non- cyclic mastalgia, it more often occurred spontaneously. The authors found that severe mastalgia runs a chronic relapsing course and often requires repeated drug treatments.

\section{Conclusions}

Mastalgia is a common symptom that causes anxiety among women and burdens healthcare facilities. The precise aetiology is unknown, but a broad classification divides mastalgia into cyclic and noncyclic forms. Careful evaluation to rule out breast cancer and reassure the patient is enough to relieve pain in many cases. In some patients, however, mastalgia is severe enough to require further evaluation and treatment. Beyond reassurance, the management options can be nonpharmacologic or pharmacologic. Surgical interventions have virtually no role in management.

\section{Competing interests}

Both authors declare that they have no competing interests related to this work.

\section{References}

1. Ader DN, South-Paul J, Adera T, Deuster PA. Cyclical mastalgia: prevalence and associated health and behavioral factors. J Psychosom Obstet Gynaecol. 2001 Jun;22(2):71-6. doi: 10.3109/01674820109049956.

2. Johnson KM, Bradley KA, Bush K, Gardella C, Dobie DJ, Laya MB. Frequency of mastalgia among women veterans association with psychiatric conditions and unexplained pain syndromes. J Gen Intern Med. 2006 Mar;21 Suppl 3:S70-5. doi: 10.1111/j.1525-1497.2006.00378.x.

3. Smith RL, Pruthi S, Fitzpatrick LA Evaluation and management of breast pain. Mayo Clin Proc. 2004 Mar;79(3):35372. doi: 10.4065/79.3.353.

4. Ader DN, Shriver CD, Browne MW. Cyclical mastalgia: premenstrual syndrome or recurrent pain disorder? J Psychosom Obstet Gynaecol. 1999 Dec;20(4):198-202. doi: 10.3109/01674829909075596.

5. Mansel RE, Webster DJT, Sweetland HM Breast pain and nodularity. In: Mansel RE, Webster DJT, Sweetland HM, editors. Benign disorders and disease of the breast. 3rd ed. Philadelphia: Saunders Elsevier; 2009. p. 107-38.

6. Kataria K, Dhar A, Srivastava A, Kumar S, Goyal A. A systematic review of current understanding and management of mastalgia. Indian J Surg. 2014 Jun;76(3):217-22. doi: 10.1007/s12262013-0813-8. Epub 2013 Feb 5.

7. Ader DN, Shriver CD. Cyclical mastalgia: prevalence and impact in an outpatient breast clinic sample. J Am Coll Surg. 1997 Nov;185(5):466-70. doi: 10.1016/S10727515(01)00956-5.
8. Scurr J, Hedger W, Morris P, Brown N. The prevalence, severity, and impact of breast pain in the general population. Breast J. 2014 Sep-Oct;20(5):508-13. doi: 10.1111/ tbj.12305. Epub 2014 Jul 7.

9. Brown N, White J, Brasher A, Scurr J. The experience of breast pain (mastalgia) in female runners of the 2012 London Marathon and its effect on exercise behavior. $\mathrm{Br} J$ Sports Med. 2014 Feb;48(4):320-5. doi: 10.1136/ bjsports-2013-092175. Epub 2013 Apr 19.

10. Malarkey WB, Schroeder LL, Stevens VC, James AG, Lanese RR. Twenty- four hour preoperative endocrine profiles in women with benign and malignant breast disease. Cancer Res. 1977 Dec;37(12):4655-9.

11. Sitruk-Ware R, Sterkers N, Mauvais-Jarvis P. Benign breast disease I: hormonal investigation. Obstet Gynecol. 1979 Apr;53(4):457-60

12. Peters F, Pickcardt CR, Zimmerman G, Breckwoldt M. PRL, TSH and thyroid hormones in benign breast diseases. Klin Wochenschr. 1981 Apr;59(8):403-7. doi: 10.1007/BF01698519.

13. Kumar S, Mansel RE, Hughes LE, Woodhead JS, Edwards CA, Scanlon MF, et al. Prolactin response to thyrotropin-releasing hormone stimulation and dopaminergic inhibition in benign breast disease Cancer. 1984 Mar 15;53(6):1311-5. doi: 10.1002/1097-0142(19840315)53:6<1311::AIDCNCR2820530615>3.0.CO;2-R.

14. Kumar S, Mansel RE, Hughes LE, Edwards CA, Scanlon MF. Prediction of response to endocrine therapy in pronounced cyclical mastalgia using dynamic tests of prolactin release. Clin Endocrinol (Oxf). 1985 Dec;23(6):699-704. doi: 10.1111/ j.1365-2265.1985.tb01131.x.
15. Preece PE, Richards AR, Owen GM, Hughes LE. Mastalgia and total body water. Br Med J. 1975 Nov 29;4(5995):498500. doi: 10.1136/bmj.4.5995.498.

16. Jenkins PL, Januil N, Gateley C, Mansel RE. Psychiatric illness in patients with severe treatment-resistant mastalgia. Gen Hosp Psychiatry. 1993 Jan;15(1):55-7. doi: 10.1016/0163-8343(93)90092-3.

17. Colegrave S, Holcombe C, Salmon P. Psychological characteristics of women presenting with breast pain. J Psychosom Res. 2001 Jun;50(6):303-7. doi: 10.1016/ S0022-3999(01)00196-9.

18. Johnson KM, Bradley KA, Bush K, Gardella C, Dobie DJ, Laya MB. Frequency of mastalgia among women veterans. Association with psychiatric conditions and unexplained pain syndromes. J Gen Intern Med. 2006 Mar;21 Suppl 3:S70-5. doi: 10.1111/j.1525-1497.2006.00378.x

19. Eren T, Aslan A, Ozemir IA, Baysal H, Sagiroglu J, Ekinci $O$, et al. Factors effecting mastalgia. Breast Care (Basel). 2016 Jun;11(3):188-93. doi: 10.1159/000444359. Epub 2016 Mar 29.

20. Minton JP, Abou-Issa H. Nonendocrine theories of the etiology of benign breast disease. World J Surg. 1989 Nov-Dec;13(6):680-4. doi: 10.1007/ BF01658414.

21. Millet AV, Dirbas FM. Clinical management of breast pain: a review. Obstet Gynecol Surv, 2002 Jul:57(7):451-61 doi: 10.1097/01.OGX.0000021529.52698.43.

22. Sharma AK, Mishra SK, Salila M, Ramesh $V$, Bal S. Cyclical mastalgia -- is it a manifestation of aberration in lipid metabolism? Indian J Physiol Pharmacol. 1994 Oct;38(4):267-71. 
23. Horrobin DF, Manku MS. Premenstrua syndrome and premenstrual breast pain (cyclical mastalgia): disorders of essential fatty acid (EFA) metabolism. Prostaglandins Leukot Essent Fatty Acids. 1989 Sep;37(4):255-61. doi: 10.1016/0952 3278(89)90036-7.

24. Morrow M. The evaluation of common breast problems. Am Fam Physician. 2000 Apr 15;61(8):2371-8, 2385.

25. Cochrane RA, Singhal $H$, Monypenny IJ, Webster DJT, Lyons K, Mansel RE. Evaluation of general practitioner referrals to a specialist breast clinic according to the UK national guidelines. Eur J Surg Oncol. 1997 Jun;23(3):198-201. doi: 10.1016/S0748-7983(97)92220-4

26. Plu-Bureau G, Thalabard JC, Sitruck-Ware R, Asselain B, Mauvains-Jarvis P. Cyclical mastalgia as a marker of breast cancer susceptibility: results of a case-control study among French women. Br J Cancer. 1992 Jun;65(6):945-9. doi: 10.1038/ bjc.1992.198.

27. Goodwin PJ, DeBoer G, Clark RM, Catton P, Redwood S, Hood N, et al. Cyclical mastopathy and premenopausal breast cancer risk. Results of a case-control study. Breast Cancer Res Treat. 1995;33(1):63-73. doi: 10.1007/BF00666072.

28. Khan SA, Apkarian AV. Mastalgia and breast cancer: a protective association? Cancer Detect Prev. 2002;26(3):192-6. doi: 10.1016/S0361-090X(02)00065-X.

29. Preece PE, Baum M, Mansel RE, Webster DJ, Fortt RW, Gravelle IH, et al. Importance of mastalgia in operable breast cancer. Br Med J (Clin Res Ed). 1982 May 1;284(6325):1299-300. doi: bmj.284.6325.1299.

30. Fariselli G, Lepera P, Viganotti G, Martell G, Bandieramonte G, Di Pietro S. Localized mastalgia as presenting symptom in breast cancer. Eur J Surg Oncol. 1988 Jun;14(3):213-5.

31. Watt-Boolsen S, Emus HC, Junge J. Fibrocystic disease and mastalgia: a histological and enzyme-histochemical study. Dan Med Bull. 1982 Jun;29(5):2524.

32. Jørgensen J, Watt-Boolsen S. Cyclical mastalgia and breast pathology. Acta Chir Scand. 1985;151(4):319-21.

33. Dupont WD, Page DL. Risk factors for breast cancer in women with proliferative breast disease. N Engl J Med. 1985 Jan 17:312(3):146-51. doi: 10.1056/ NEJM198501173120303.

34. Hughes LE. Benign breast disordersintroduction fibrocystic disease? Non-disease? or ANDI? World J Surg. 1989 Nov;13(6):667-8. doi: 10.1007/ BF01658411.
35. Habor V, Habor A, Copotoiu C, Pantîru A. [Fibrocystic breast disease-breast cancer sequence]. [Article in Romanian]. Chirurgia (Bucur). 2010 MarApr;105(2):191-4

36. Ramakrishnan R, Werbeck J, Khurana KK, Khan SA. Expression of interleukin-6 and tumor necrosis factor alpha and histopathologic findings in painful and non-painful breast tissue. Breast J. 2003 Mar-Apr;9(2):91-7. doi: 10.1046/j.15244741.2003.09206.x

37. Masroor I, Afzal S, Sakhawat S. Negative predictive value of mammography and sonography in mastalgia with negative physical findings. J Pak Med Assoc. 2009 Sep;59(9):598-601.

38. Khan SA, Apkarian AV. The characteristics of cyclical and noncyclical mastalgia: a prospective study using a modified McGill Pain Questionnaire. Breast Cance Res Treat 2002 Sep:75(2):147-57. doi: 10.1023/A:101968582

39. Ashley B. Mastalgia. Lippincotts Prim Care Pract. 1998 Mar-Apr;2(2):189-93.

40. Rodden AM. Common breast concerns Prim Care. 2009 Mar;36(1):103-13, viii. doi: 10.1016/j.pop.2008.10.006.

41. Barros AC, Mottola J, Ruiz CA, Borges MN, Pinotti JA. Reassurance in the treatment of mastalgia. Breast J. 1999 May;5(3):162-165. doi: 10.1046/j.15244741.1999.98089.x

42. Vaidyanathan L, Barnard K, Elnicki DM Benign breast disease: when to treat when to reassure, when to refer. Cleve Clin J Med. 2002 May;69(5):425-32.

43. BeLieu RM. Mastodynia. Obstet Gynecol Clin North Am. 1994 Sep;21(3):461-77

44. Hadi MS. Sports brassiere: is it a solution for mastalgia? Breast J. 2000 Nov;6(6):407-409. doi: 10.1046/j.15244741.2000.20018x

45. Wilson MC, Sellwood RA. Therapeutic value of a supporting brassiere in mastodynia. $\mathrm{Br}$ Med J. $1976 \mathrm{Ju}$ 10;2(6027):90. doi: 10.1136/bmj.2.6027.90.

46. Genc A, Celebi MM, Celik SU, Atman ED Kocaay AF, Zergeroglu AM, et al. The effects of exercise on mastalgia. Phys Sportsmed. 2017 Feb;45(1):17-21. doi: 10.1080/00913847.2017.1252702. Epub 2016 Nov 3.

47. Goodwin PJ, Miller A, Del Guidice ME Singer W, Connelly P, Knox Ritchie JW. Elevated high-density lipoprotein cholesterol and dietary fat intake in women with cyclic mastalgia. Am Obstet Gynecol. 1998 Aug;179(2):430-7. doi: 10.1016/S0002-9378(98)70375-8.

48. Boyd NF, McGuire V, Shannon P, Cousins M, Kriukov $V$, Mahoney $L$, et al. Effect of a low-fat high-carbohydrate diet on symptoms of cyclical mastopathy. Lancet. 1988 Jul 16;2(8603):128-32. doi: 10.1016/ 50140-6736(88)90684-8
49. Anjum S, ,Mahmood S, Raza A. Effect of caffeine intake on mastalgia. J Islamabad Med Dent Coll. 2016;5(2):88-91.

50. Fox H, Walker LG, Heys SD, Ah-See AK, Eremin $\mathrm{O}$. Are patients with mastalgia anxious, and does relaxation therapy help? Breast. 1997 Jun;6(3):138-42. doi: 10.1016/S0960-9776(97)90554-3.

51. Mansel RE, Pye JK, Hughes LE. Effects of essential fatty acids on cyclical mastalgia and noncyclical breast disorders. In Horrobin DF, editor. Omega-6 essential fatty acids: pathophysiology and roles in clinical medicine. New York: Wiley-Liss; 1990. p. 557-67.

52. Puolakka J, Makarainen L, Viinikka L, Ylikorkala O. Biochemical and clinical effects of treating the premenstrual syndrome with prostaglandin synthesis precursors. J Reprod Med. 1985 Mar;30(3):149-53.

53. Collins A, Cerin A, Coleman G, Landgren BM. Essential fatty acids in the treatment of premenstrual syndrome. Obstet Gynecol. 1993 Jan;81(1):93-8.

54. Khoo SK, Munro C, Battistutta D. Evening primrose oil and treatment of premenstrual syndrome. Med J Aust. 1990 Aug 20;153(4):189-92.

55. Pruthi S, Wahner-Roedler DL, Torkelson CJ, Cha SS, Thicke LS, et al. Vitamin E and evening primrose oil for management of cyclical mastalgia: a randomized pilot study. Altern Med Rev. 2010 Apr;15(1):5967.

56. Blommers J, de Lange-De Klerk ES, Kuik DJ, Bezemer PD, Meijer S. Evening primrose oil and fish oil for severe chronic mastalgia: a randomized, double-blind, controlled trial. Am J Obstet Gynecol. 2002 Nov;187(5):1389-94. doi: 10.1067/ mob.2002.127377a.

57. Ingram DM, Hickling C, West L, Mahe $\downarrow$, Dunbar PM. A double-blind randomized controlled trial of isoflavones in the treatment of cyclical mastalgia. Breast. 2002; 11:170-4

58. Goss PE, Li T, Theriault M, Pinto $S$, Thompson L. Effects of dietary flaxseed in women with cyclical mastalgia [abstract 153]. In: 23rd Annual San Antonio Breast Cancer Symposium. December 6-9, 2000. Abstracts. Breast Cancer Res Treat. 2000 Nov;64(1):26-146.

59. Huseini HF, Kianbakht S, Mirshamsi MH Zarch AB. Effectiveness of topical Nigella sativa seed oil in the treatment of cyclic mastalgia: a randomized, triple-blind, active, and placebo-controlled clinical trial. Planta Med. 2016 Mar:82(4):285-8. doi: 10.1055/s-0035-1558208. Epub 2015 Nov 19.

60. Carmichael AR. Can Vitex agnus castus be used for the treatment of mastalgia? What is the current evidence? Evid Based Complement Alternat Med. 2008 Sep;5(3):247-50. doi: 10.1093/ecam/ nem074. 
61. Halaska, M. Beles P, Gorkow C, Sieder C. Treatment of cyclical mastalgia with a solution containing a Vitex agnus castus extract: results of a placebocontrolled double-blind study. Breast. 1999 Aug;8(4):175-81. doi: 10.1054/ brst.1999.0039.

62. Saied GM, Kamel RM, Dessouki N. Low intensity laser therapy is comparable to bromocriptine-evening primrose oil for the treatment of cyclical mastalgia in Egyptian females. Tanzan Health Res Bull. 2007 Sep;9(3):196-201.

63. McFadyen IJ, Raab GM , Macintyre CC , Forrest AP. Progesterone cream for cyclic breast pain. BMJ. 1989 Apr 8;298(6678):931. doi: 10.1136/ bmj.298.6678.931.

64. Maddox PR, Harrison BJ, Horobin JM, Walker K, Mansel RE, Preece PE, et al. A randomized controlled trial of medroxyprogesterone acetate in mastalgia. Ann R Coll Surg Engl. 1990 Mar;72(2):71-6.

65. Nappi C, Affinito P, DiCarlo C, Esposito G, Montemagno U. Double-blind controlled trial of progesterone vaginal cream treatment for cyclical mastodynia in women with benign breast disease. J Endocrinol Invest. 1992 Dec;15(11):801-6. doi: 10.1007/BF03348808.

66. Rathi J, Chawla I, Singh K, Chawla A. Centchroman as first-line treatment for mastalgia: Results of an open-label, singlearm trial. Breast J. 2016 Jul;22(4):407-12. doi: 10.1111/tbj.12593. Epub 2016 Apr 5.

67. Dhar A, Srivastava A. Role of centchroman in regression of mastalgia and fibroadenoma. World J Surg. 2007 Jun;31(6):1178-84. doi: 10.1007/s00268007-9040-4.

68. Tejwani PL, Srivastava A, Nerkar H, Dhar A, Hari S, Thulkar S, et al. Centchroman regresses mastalgia: a randomized comparison with danazol. Indian J Surg. 2011 Jun;73(3):199-205. doi: 10.1007/ s12262-010-0216-z. Epub 2010 Nov 30.

69. Hamed $H$, Kotheri A, Beechey-Newman $\mathrm{N}$, Fentiman IS. Toremifene, a new agent for treatment of mastalgia: an open study. Int J Fertil Womens Med. 2004 NovDec;49(6):278-80.
70. Gong C, Song E, Jia W, Qin L, Guo J, Jia $\mathrm{H}$, et al. A double-blind randomized controlled trial of toremifen therapy for mastalgia. Arch Surg. 2006 Jan;141(1):437. doi: 10.1001/archsurg.141.1.43.

71. Irving AD, Morrison SL. Effectiveness of topical non-steroidal anti-inflammatory drugs in the management of breast pain. J R Coll Surg Edinb. 1998 Jun;43(3):158-9.

72. Colak T, IpekT, Kanik A, Ogetman Z, Aydin S. Efficacy of topical nonsteroidal drugs in mastalgia treatment. J Am Coll Surg. 2003 Apr;196(4):525-30. doi: 10.1016/S10727515(02)01893-8.

73. Mansel RE, Wisbey JR, Hughes LE. Controlled trial of the antigonadotropin danazol in painful nodular benign breast disease. Lancet. 1982 Apr 24;1(8278):92830. doi: 10.1016/S0140-6736(82)91932-8.

74. Ortiz-Mendoza CM, Olvera-Mancilla M. [Danazol effectivity in control of moderate to severe mastalgia]. [Article in Spanish]. Cir Cir. 2004 Nov-Dec;72(6):479-82.

75. O'Brien PM, Abukhalil IE. Randomized controlled trial of the management of premenstrual syndrome and premenstrual mastalgia using luteal phase-only danazol. Am J Obstet Gynecol. 1999 Jan;180(1 Pt 1):18-23. doi: 10.1016/S0002-9378(99)70142-0.

76. Maddox PR, Harrison BJ, Mansel RE. Lowdose danazol for mastalgia. Br J Clin Pract Suppl. 1989 Nov;68:43-7; discussion 4953.

77. Harrison BJ, Maddox PR, Mansel RE. Maintenance therapy of cyclical mastalgia using low-dose Danazol. J R Coll Surg Edinb. 1989 Apr:34(2):79-81.

78. Ortiz-Mendoza CM, Lucas Flores MA Domville Ede G. [Mastalgia treatment with tamoxifen]. [Article in Spanish]. Ginecol Obstet Mex. 2003 Oct;71:502-7.

79. Fentiman IS, Caleffi M, Brame K, Chaudary MA, Hayward JL. Double-blind controlled trial of tamoxifen therapy for mastalgia. Lancet. 1986 Feb 8;1(8476):287-8. doi: 10.1016/S0140-6736(86)90825-1.
80. Kontostolis E, Stefanidis K, Navrozoglou I, Lolis D. Comparison of tamoxifen with danazol for treatment of cyclical mastalgia. Gynecol Endocrinol. 1997 Dec;11(6):3937. doi: 10.3109/09513599709152566.

81. Jain BK, Bansal A, Choudhary D, Garg PK, Mohanty D. Centchroman vs tamoxifen for regression of mastalgia: a randomized controlled trial. Int J Surg. 2015 Mar;15:116. doi: 10.1016/j.ijsu.2014.12.033. Epub 2015 Jan 22.

82. Srivastava A, Mansel RE, Arvinda N. Evidence-based management of mastalgia: a meta-analysis of randomized trials. Breast. 2007 Oct;16(5):503-12. doi: 10.1016/j.breast.2007.03.003. Epub 2007 May 16.

83. Mansel RE, Dogliotti L. European multicentre trial of bromocriptine in cyclical mastalgia. Lancet. 1990 Jan 27;335(8683):190-3. doi: 10.1016/01406736(90)90278-D.

84. Nazli K, Syed S, Mahmood MR, Ansari F. Controlled trial of the prolactin inhibitor bromocriptine (Parlodel) in the treatment of severe cyclical mastalgia. Br J Clin Pract. 1989 Sep;43(9):322-7.

85. Davies EL, Cochrane RA, Stansfield K, Sweetland HM, Mansel RE. Is there a role for surgery in the treatment of mastalgia? Breast. 1999 Oct;8(5):285-8. doi: 10.1054/ brst.1999.0065.

86. Steinbrunn BS, Zera RT, Rodriguez JL. Mastalgia: tailoring treatment to type of breast pain. Postgrad Med. 1997 Nov;102(5):183-4, 187-9, 193-4 passim. doi: 10.3810/pgm.1997.11.369.

87. Davies EL, Gateley CA, Miers M, Mansel RE. The long-term course of mastalgia. J R Soc Med. 1998 Sep;91(9):462-4. 